\title{
Perancangan Android Package Mobile Web pada Sistem Penilaian di Perguruan Tinggi
}

\section{Designing Android Mobile Web Package on Assessment System in Higher Education}

\author{
Diah Aryani ${ }^{1}$, Qurotul Aini ${ }^{2}$, Fernanda Setyobudi Armansyah ${ }^{3}$ \\ Dosen Perguruan Tinggi Raharja Program Teknik Informatika ${ }^{1}$, Dosen Perguruan Tinggi \\ Raharja Program Sistem Informasi ${ }^{2}$, Mahasiswa Perguruan Tinggi Raharja Jurusan Sistem \\ Informasi $^{3}$

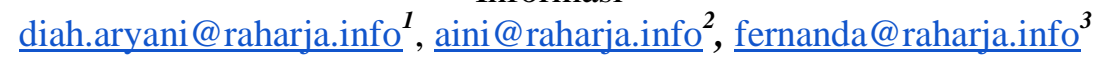

\begin{abstract}
Abstrak
Sistem Penilaian Plus adalah sebuah sistem yang telah ada di Perguruan Tinggi Raharja untuk membantu dosen dalam menginput nilai dan juga mahasiswa untuk mengakses nilai kelas. Namun metode akses yang digunakan hanya melalui sebuah PC. Dan itu membatasi pengguna jika ingin menggunakan penilaian plus di luar berbagai mobilitas yang dirasakan. Maka Android Packaging di perlukan untuk membangun sebuah metode akses baru, yaitu di sebuah mobile device dengan webview. Hasilnya sebuah Android Packaging penilaian plus yang sudah ada, akan di kombinasikan dengan Google Play. Dengan tujuan pengguna dapat menemukan penilaian plus dengan mudah. Dan hasilnya, feedback yang di dapatkan mencapai 576 Downloader dan 352 Rating Review. Dapat di simpulkan bahwa sebuah sistem yang di build sebagai Android Packaging dengan hasil webview cukup membantu pengguna dalam mengoperasikan sistem dengan mobile device.
\end{abstract}

Kata kunci-Sistem Penilaian, Mobilitas, Mobile Device, Android Packaging

\begin{abstract}
Rating System Plus is a system that already exist in Raharja Higher Education to assist lecturers in input value and also students to access grade value. However, access methods are used only through a PC. And that limits users if they want to use a plus rating beyond the perceived mobility. Then Android Packaging is needed to build a new access method, namely in a mobile device with webview. The result is an Android Packaging plus assessment that already exists, will be combined with Google Play. With the purpose of the user can find the plus assessment easily. And the result, the feedback that got reached 576 Downloader and 352 Rating Review. Can be concluded that a system that is built as Android Packaging with the results of webview enough to assist users in operating the system with a mobile device.
\end{abstract}

Keywords-Assessment System, Mobility, Mobile Device, Android Packaging.

\section{PENDAHULUAN}

Meningkatnya harapan masyarakat luas dalam perkembangan teknologi khususnya perkembangan sistem yang dapat di akses di dalam sebuah mobile device sangat tinggi. Tidak begitu pula di Perguruan Tinggi Raharja. Telah banyak sistem yang di kembangkan dan sudah digunakan, namun yang berbasis mobile apps atau mobile web masih belum begitu banyak. Sebuah informasi yang cepat dan tepat menjadi sebuah tolak ukur untuk menilai kualitas yang ada di Perguruan Tinggi Raharja. Salah satunya ada di dalam sebuah sistem penilaian yang telah ada dan sudah di gunakan oleh bapak ibu dosen terkait. Penilaian adalah proses menentukan nilai suatu subjek dengan menggunakan ukuran atau kriteria tertentu. Perkembangan yang 
intensif secara keseluruhan pun dilakukan guna memberikan rasa penggunaan sistem yang baik untuk dosen.

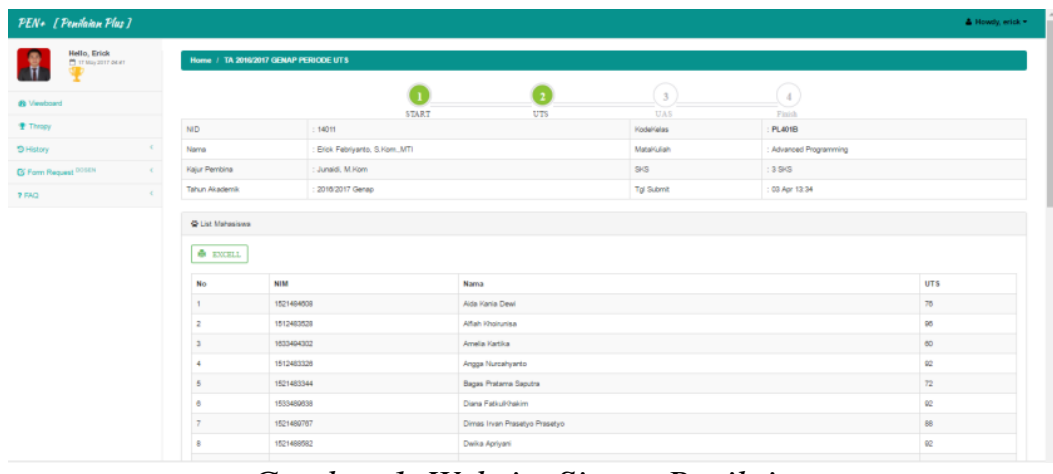

Gambar 1. Website Sistem Penilaian

Namun, karena mobilitas yang tinggi, menghalangi kinerja dosen dalam menggunakan sistem penilaian yang berdampak negatif terhadap kinerja dan pandangan mahasiswa nya. Maka dari itu dibutuhkan pengembangan baru yang mampu memberikan banyak opsi bagi bapak ibu dosen, seperti mengembangkan sistem penilaian tersebut ke dalam sebuah mobile web, yang dimana memberikan banyak opsi untuk dosen sebagai pengguna yang dimana akan menjadi peningkatan mutu di dalam Perguruan Tinggi Raharja.

Android Package adalah sebuah format berkas yang digunakan untuk mendistribusikan dan memasang software dan middleware ke smartphone dengan sistem operasi Android. Maka sistem penilaian yang telah ada akan di kemas di dalam satu Android Package guna bisa membawanya ke dalam tempat pengunduhan bagi pengguna smartphone berbasis Android, yaitu Playstore. Dan Android Studio akan menjadi tools dalam perancangan Android Package untuk sistem penilaian Perguruan Tinggi Raharja.

Dalam penelitian ini di lakukan 7 tinjauan pustaka terhadap penelitian terdahulu untuk menjadi pedoman di dalam pengembangan ini. Sistem operasi Android saat ini merupakan salah satu dari sekian banyak sistem operasi pada smartphone yang sedang mengalami pertumbuhan pesat di dunia, khususnya di Indonesia. CV.Vitiga Tekno Indonesia bergerak di bidang pemasaran gadget membutuhkan media marketing yang dapat diakses secara online selain website yaitu melalui smartphone. Oleh karena itu penelitian ini berfokus pada bagaimana membuat aplikasi mobile e-commerce pada smartphone Android, dengan cara mengambil data yang berasal dari website, dan kemudian ditampilkan ke dalam sebuah aplikasi,menggunakan metode HTTP Connection dan JSON Parsing. Pembuatan aplikasi menggunakan bahasa pemrograman Java, dengan bantuan tools IDE Eclipse dan MySQL untuk database server. JSON berkomunikasi melalui Application Program Interface (API) bertujuan untuk menghubungkan aplikasi mobile dengan database yang ada di dalam server. Pada penelitian ini API adalah kumpulan source codePHP, yang isinya adalah query untuk mengambil data dari website, yang hasilnya di-encode ke dalam bentuk JSON.

Dalam menentukan dan mengambil suatu keputusan pada suatu perusahaan atau instansi diperlukan data-data yang diolah menjadi suatu informasi yang berguna bagi pihak pengambil keputusan. Universitas Widyatama sebagai instansi pendidikan memiliki data-data yang banyak dan sangat vital, untuk mengelola data-data tersebut dibutuhkan sebuah perancangan Data Warehouse sebagai sarana pengambilan keputusan. Salah satu masalah yang ada yaitu walaupun Data Warehouse tersebut sudah diterapkan di Universitas Widyatama tidak semua lapisan instansi bisa mendapatkan informasi data-data seputar perkuliahan. Agar memudahkan hal tersebut harus dibuat sebuah sistem informasi dengan ruang lingkup pengguna masyarakat kampus, salah satunya dosen. Yaitu dengan dibuat mobile application yang berfungsi sebagai 
media untuk mengetahui informasi seputar perkuliahan seperti penjadwalan, absensi, reschedulling dan informasi kampus mulai dari akademis sampai dengan non akademis. Untuk perancangan aplikasi dalam pengintegrasian data dan penentuan service memanfaatkan SOA dengan pendekatan terhadap sifat SOA itu sendiri, Aplikasi ini juga dilengkapi dengan fitur seperti reminder countdown mata kuliah dan image-slider yang berfungsi untuk menampilkan event atau jadwal-jadwal tertentu akan atau tengah berlangsung agar mengurangi kemungkinan keterlambatan yang masih sering terjadi. Aplikasi dibuat menggunakan pemograman web seperti HTML 5, CSS, PHP, dan Javascript yang nantinya akan dirubah menjadi Mobile Apps menggunakan Webview serta untuk pengelolaan database menggunakan MySQL, data nya sendiri didapatkan menggunakan url yang dihasilkan melalui proses web service. Sistem operasi yang mendukung aplikasi ini adalah Android dengan versi minimal Jellybean.

Pada zaman sekarang teknologi semakin berkembang, popularitas teknologi web dan internet berkembang pesat. Di bidang akademik, salah satu penggunaan web di manfaatkan untuk mendapatkan informasi mengenai perkuliahan, nilai, jadwal, dan dan lain-lain. Smartphone atau perangkat mobile menjadi salah satu perangkat yang paling populer digunakan untuk mengakses internet, karena memudahkan pengguna untuk mengetahui informasi lebih cepat dan tepat. Suatu kendala apabila membuka web di mobile seringkali konten atau tampilan menjadi berantakan atau tidak responsif. Teknologi android studio webview dapat menjadi suatu solusi agar konten web yang diakses melalui mobile menjadi responsif. Dalam penelitian ini yang penulis lakukan adalah membangun sistem portal mahasiswa agar menjadi lebih baik ketika digunakan dengan mobile yang mendukung multi platform. Dengan memanfaatkan web service dalam pengambilan data nya. Menggunakan web service, memungkinkan pengambilan data dari sistem akademik universitas widyatama secara aman, karena tidak langsung mengakses ke database melainkan melalui perantara web service. Dengan penelitian ini diharapkan dapat menjadi alternatif bagi mahasiswa yang ingin mendapatkan informasi yang lebih cepat dan tepat melalui mobile dengan tampilan yang responsif.

Musyawarah perencanaan pembangunan pada Pemerintah Kota Yogyakarta dilaksanakan secara berjenjang mulai dari tingkat kelurahan, kecamatan, hingga kota. Kualitas usulan kewilayahan yang dihasilkan dari penyelenggaraan musyawarah perencanaan pembangunan kelurahan yang mengakomodir kepentingan masyarakat yang ada di wilayah. Saat ini pelaksanaan musyawarah perencanaan pembangunan pada Pemerintah Kota Yogyakarta masih manual. Masyarakat umum terkendala dalam menyampaikan usulan dan memantau usulan secara real time. Proses rekapitulasi usulan musyawarah perencanaan pembangunan sering terkendala oleh format file yang tidak seragam sehingga memakan waktu lama dan rentan terhadap kesalahan. Informasi terkait aturan, pelaksanaan, agenda dan hasil musyawarah perencanaan pembangunan belum terinformasikan dengan baik. Penelitian ini bertujuan untuk mengembangkan purwarupa sistem informasi yang dapat memfasilitasi monitoring usulan dan pelaksanaan musyawarah perencanaan pembangunan dari level masyarakat sampai dengan usulan diterima pada level kota. Purwarupa e-Musrenbang dikembangkan dengan menggunakan model incremental. Pengembangan purwarupa e-Musrenbang berbasis web menggunakan framework Bootstrap untuk frontend dan CMS Lokomedia untuk backend. Appsgeyser digunakan dalam pengembangan e-Musrenbang mobile berbasis Android untuk mengubah konten web ke dalam aplikasi Android. Penelitian ini menghasilkan purwarupa e-Musrenbang dengan mengintegrasikan media website dan aplikasi mobile berbasis Android sehingga masyarakat dapat mengakses data musyawarah perencanaan pembangunan dengan lebih leluasa, meningkatkan partisipasi masyarakat dalam musyawarah perencanaan pembangunan, memudahkan masyarakat dalam memantau usulan pembangunan dan mewujudkan tata kelola dokumen usulan pembangunan yang baik.

Pola iklim dan cuaca di Indonesia yang tidak berาaturan dan eskstrim akan mengganggu transportasi laut. Pada penelitian ini telah dilakukan perancangan prediktor cuaca 
maritim berbasis logika fuzzy takagi sugeno menggunakan user interface smartphone android. User interface smar $\neg \neg$ phone an $\neg$ droid dipilih karena android banyak digunakan masy $\neg$ arakat indonesia. Data yang digunakan untuk membangun basis atu $\neg$ ran dan fungsi keanggotaan berasal dari data BMKG II Perak yang direkam perjam selama 6 tahun yaitu dari januari 2007 hingga desember 2012. Digunakan data cuaca maritim dari tahun 2007 hingga 2012 untuk membangun basis aturan dan fungsi keanggotaan logika fuzzy. Validasi prediksi cuaca maritim di-lakukan dengan menggunakan data BMKG bulan februari 2013. Selain menggunakan data BMKG juga dilakukan validasi real ᄀtime menggunakan data maritim buoyweather. Hasil pene $\neg$ litian didapatkan akurasi prediksi cuaca maritim tertinggi, yaitu: suhu udara, kelembaban udara, kecepatan arus laut, tinggi gelombang dan curah hujan adalah $83 \%$, $84.5 \%, 87 \%, 85.7 \%$ dan $95 \%$.

Daerah Istimewa Yogyakarta merupakan kota pelajar dan memiliki banyak perguruan tinggi. Karena begitu banyaknya perguruan tinggi, akan menyebabkan para calon mahasiswa baru mengalami kesulitan dalam mencari informasi seputar perguruan tinggi di Daerah Istimewa Yogyakarta. Selain itu, setiap perguruan tinggi memiliki program studi yang berbedabeda. Oleh karena itu, penulis menerapkan implementasi MVC (Model-View-Controller) pada situs portal pencarian universitas di Daerah Istimewa Yogyakarta. MVC merupakan suatu metode yang digunakan penulis untuk merancang sistem berbasis website. Tampilan (view) website dihasilkan dari pengolahan database yang terdapat dalam model. Proses pengolahan tersebut dengan menggunakan query SQL (Structured Query Language). Agar hasil dari pengolahan database tersebut dapat ditampilkan, maka diperlukan controller untuk menghubungkan model dengan view. Hasil dari implementasi MVC (Model-View-Controller) pada situs portal ini ternyata dapat membantu calon mahasiswa baru untuk mengetahui perguruan tinggi apa saja yang tersedia di Daerah Istimewa Yogyakarta dan dapat melakukan pencarian perguruan tinggi yang diinginkan beserta peta lokasinya. Sehingga dapat disimpulkan bahwa penggunaan MVC sangat berperan penting dalam pembuatan situs portal pencarian universitas di Daerah Istimewa Yogyakarta.

TIKI (titipan kilat) adalah suatu jasa pengiriman barang domestik maupun internasional. TIKI sendiri sudah memiliki sistem yang sudah berjalan dan sistem itu berupa website dinamis yang hanya bisa digunakan menggunakan browser internet. Saat ini sistem operasi open source android berkembang sangat pesat dan menanjak popularitasnya karena berani menyaingi menyaingi sistem operasi mobile lain seperti ios, blackberry atau windows phone. Hal ini mendorong untuk memaksimalkan potensi yang dimiliki oleh sistem operasi android, dengan membangun sebuah aplikasi GPS (Geographic Positioning System) dengan menggunakan Google Maps untuk pencarian lokasi agen TIKI di Yogyakarta. Aplikasi ini diharapkan agar para pengguna TIKI tidak repot untuk membuka sistem yang ada di website TIKI karena aplikasi ini bisa digunakan di perangkat mobile yang ada dengan sistem operasi Android. Aplikasi ini diharapkan mempermudah pengguna aplikasi untuk melihat data nomor resi untuk pelacakan barang yang dikirim dengan fitur cek resi. Fitur TIKI terdekat adalah fitur yang akan menampilkan rute terdekat menuju lokasi agen TIKI dari posisi pengguna aplikasi berada menuju ke lokasi agen TIKI yang dituju dan bisa mempelihatkan dimana letak agen TIKI itu berada dengan tampilan marker yang berwarna biru yang berada di maps. Aplikasi pencarian lokasi agen TIKI ini dibangun menggunakan bahasa pemrograman php dan pengolahan database menggunakan MySQL. Software Eclipse juga mendukung pembuatan aplikasi ini karena aplikasi ini memerlukan bahasa pemrograman Java, agar dapat diterapkan pada perangkat mobile berbasis Android.

\section{METODE PENELITIAN}

Terdapat 4 tahapan yang digunakan dalam penyusunan penelitian ini menggunakan metode pengembangan sistem, sebagai berikut: 
a. Requirements analysis and definition, pada tahap ini mengumpulkan kebutuhan secara lengkap kemudian di analisis dan di definisikan kebutuhan yang harus di penuhi oleh program yang akan di bangun. Analisa yang harus ada berupa sistem web yang sudah berjalan seperti penilaian plus, tools yang ada seperti Android Studio. Lalu me-manage semuanya dengan baik agar tahap awal berjalan dengan sukses.

b. System and software design, pada tahap ini desain di kerjakan setelah kebutuhan selesai di kumpulkan secara lengkap. Jika semua Analisa dan Tools telah siap, maka metode system and software design dibutuhkan untuk menggambarkan alur berjalan yang telah ada dan yang akan dikembangkan. Sama halnya dengan penilaian plus yang saat ini berjalan hanya bisa di akses menggunakan PC, akan dikembangkan untuk bisa di akses di sebuah mobile device.

c. Implementation and unit testing, pada tahap ini desain program di terjemahkan ke dalam kode-kode dengan bahasa pemrograman yang sudah di tentukan. Program yang dibangun langsung di uji baik secara unit. Dimana jika semuanya telah selesai, maka feedback dari pengguna pun dibutuhkan. Dibutuhkan sebuah implementasi yang kuat ke dosen dan mahasiswa sebagai ujicoba sistem yang telah selesai.

d. Operation and maintenance, mengoperasikan program di lingkungannya dan melakukan pemeliharaan, seperti penyesuaian atau perubahan karena adaptasi dengan situasi sebenarnya. Maka jika sistem telah selesai, pemeliharaan pun wajib dilakukan. Seperti perbaikan bug yang mungkin akan di temukan oleh dosen dan mahasiswa dalam menggunakan sistem penilaian penplus.

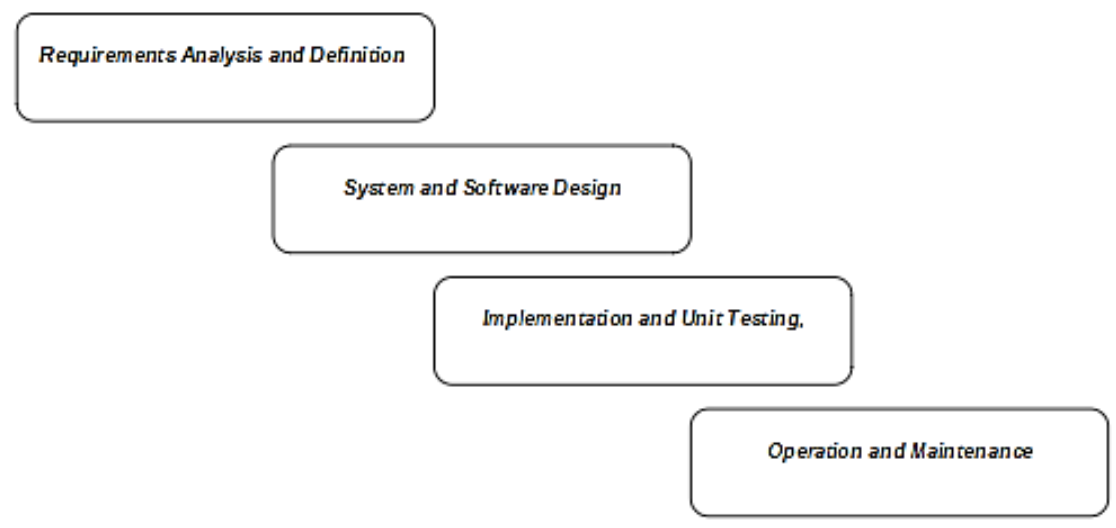

Gambar 2. Metode Pengembangan Sistem

\section{HASIL DAN PEMBAHASAN}

Di dalam sebuah perancangan, langkah awal yang harus di lakukan adalah mempersiapkan alat dan bahan yang akan digunakan. Lalu lanjut ke dalam sebuah proses building, dimana proses inti ini di lakukan sebagai tahapan besar dalam pengembangan suatu sistem. Jika telah selesai akan berlanjut ke dalam tahapan implementasi, dimana tahap ini akan menjadi tahapan titik nilai sukses atau tidaknya sistem yang telah di bangun.

3,1 Alat dan Bahan

3.1.1 Sistem Penilaian Perguruan Tinggi Raharja

Vol. 7, No. 2, Juli 2017 


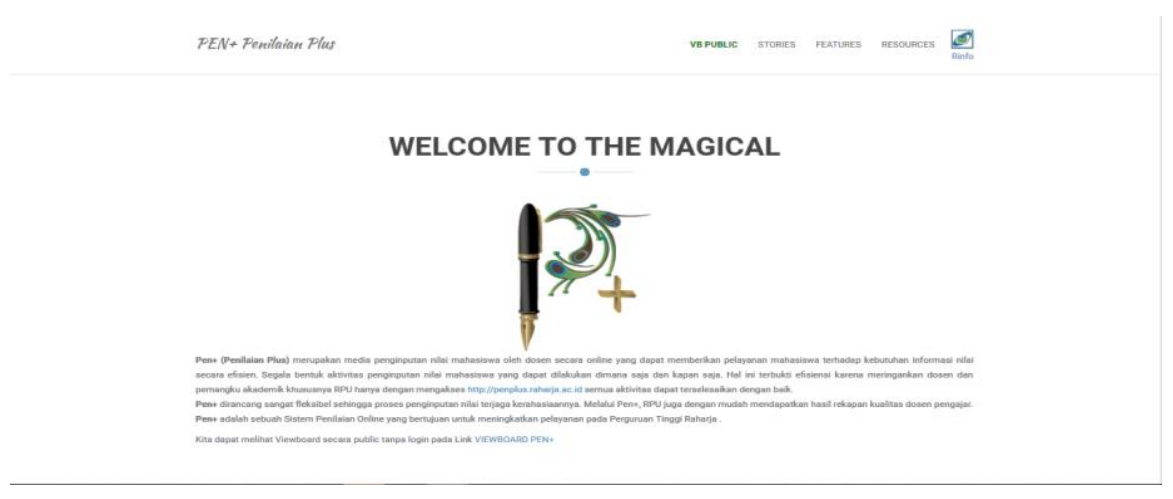

Gambar 3. Sistem Penilaian Pen+

Sistem penilaian Perguruan Tinggi Raharja yaitu Pen+ yang bisa di akses pada http://penplus.raharja.ac.id/. Pen+ atau Penilaian Plus adalah media penginputan nilai mahasiswa yang di lakukan oleh dosen secara online. Fasilitas ini merupakan pelayanan untuk mahasiswa dalam mendapatkan informasi nilai secara efisien. Berbagai bentuk aktivitas penginputan nilai mahasiswa dapat dilakukan dimana saja dan kapan saja. Sistem ini terbukti efisiensi karena dapat meringankan pekerjaan dosen dan pemangku akademik khususnya RPU hanya dengan mengakses http://penplus.raharja.ac.id semua aktivitas dapat terselesaikan dengan baik. Pen+ dirancang sangat fleksibel sehingga proses penginputan nilai terjaga kerahasiaan nya. Melalui Pen+, RPU juga dengan mudah mendapatkan hasil rekapan kualitas dosen pengajar. Pen+ adalah sebuah Sistem Penilaian Online yang bertujuan untuk meningkatkan pelayanan pada Perguruan Tinggi Raharja.

\subsubsection{Android Studio}

Android Studio merupakan aplikasi yang diperkenalkan oleh google untuk pengembangan Android Development pada acara Google I/O 2013. Android merupakan pemutakhiran dari Eclipse dan dibuat sesuai IDE Java.

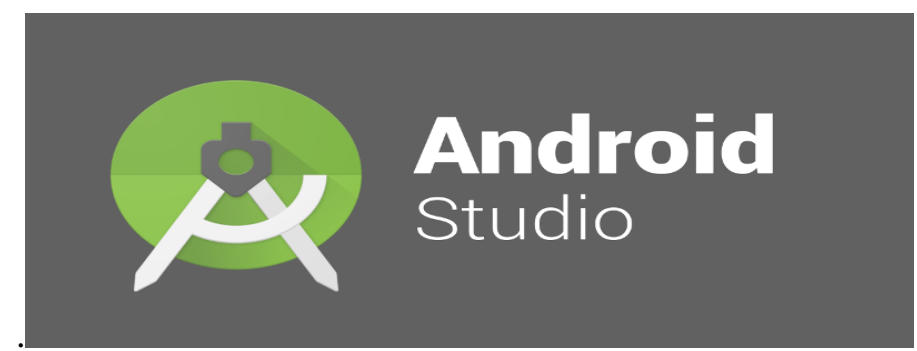

Gambar 4. Android Studio

Sebagai pengembangan dari Eclipse, Android Studio mempunyai banyak fitur-fitur baru dibandingkan dengan Eclipse IDE. Maka dari segi penggunaan dan fitur, Android Studio telah mendapatkan dukungan penuh untuk mempermudah penggunanya.

\subsubsection{Device Android}




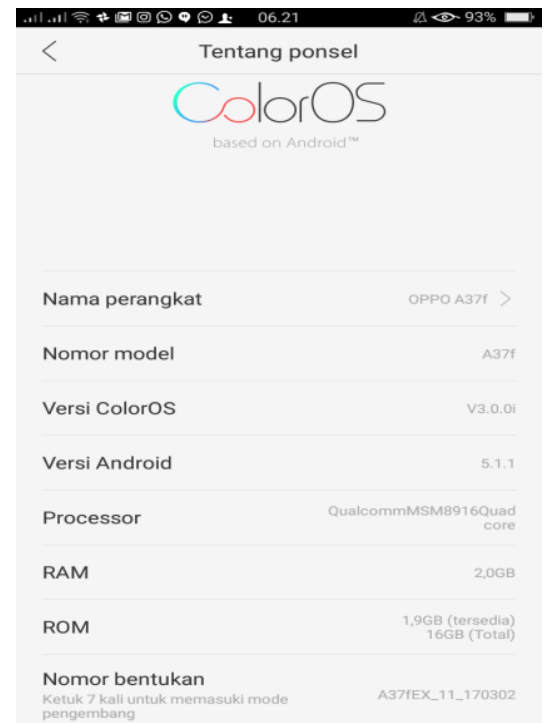

Gambar 5. Spesifikasi Device

Dalam pengembangan ini, device android wajib di gunakan sebagai alat uji coba aplikasi yang akan berjalan. Kali ini Oppo A37F digunakan sebagai alat uji coba. Dengan Processor Quad Core, Ram 2GB, Rom 1.9GB dan Android Version 5.1.1 sudah mumpuni untuk menjalankan sebuah webview.

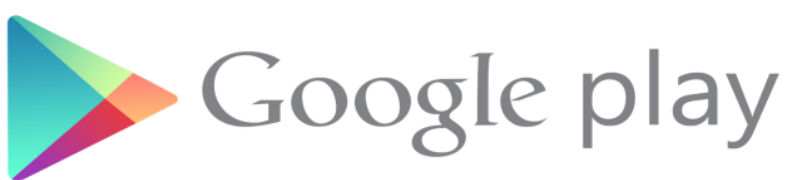

Gambar 6. Google Play

Google Play adalah layanan digital yang dimiliki oleh Google. Yang juga melingkupi toko digital yang berisi seperti aplikasi, games, book, music dan banyak hal lainnya. Layanan ini dapat diakses baik melalui aplikasi device (Android), Web dan Google TV. Android Packaging sistem penilaian yang telah selesai akan di upload ke dalam Play Store. Untuk mempermudah user dalam menemukan dan menggunakan Pen+ dimana saja dan kapan saja.

\subsection{Proses Building}

Langkah awal yang harus di lakukan adalah membuka Android Studio, dan membuat id project sesuai yang di inginkan. Disini Penplus menjadi application name yang akan digunakan.

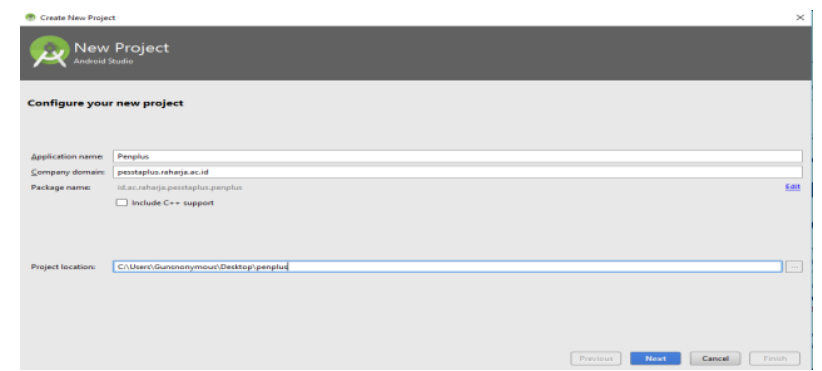

Gambar 7. Create New Project

Selanjutnya pilih Phone dan Tablet sebagai device yang akan digunakan untuk aplikasi 
ini. Dan pilih SDK yang akan digunakan. Seperti diketahui SDK atau disebut juga software development kit adalah satu set alat pengembangan yang digunakan untuk mengembangkan aplikasi pada platform android. Fungsinya adalah untuk dapat memuat fitur terbaru, maka pengembang harus mendownload dan menginstall SDK untuk masing-masing device phone.

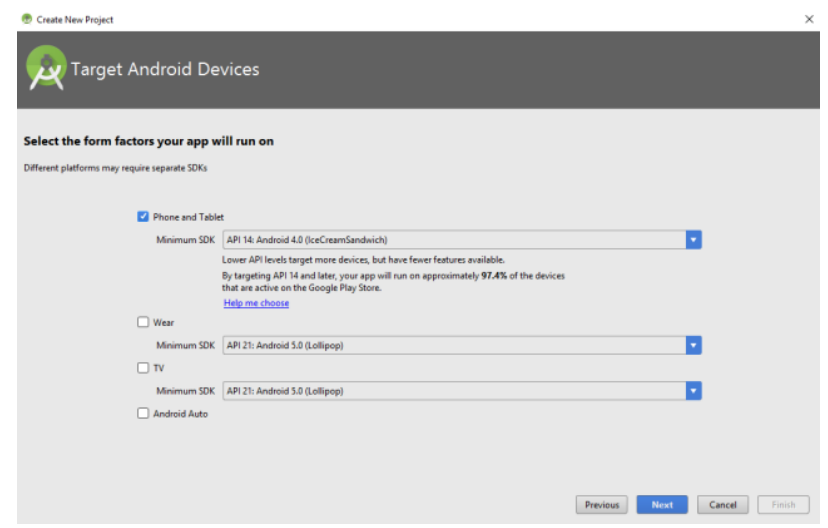

Gambar 8. Target Android Device

Dan pilih empty activity sebagai aktivitas yang akan kita lakukan. Empty activity di pilih karena dalam proses ini kita tidak menggunakan activity yang lainnya seperti, fullscreen activity, login activty, scrolling activity dan activity lainnya. Karena pada dasarnya kita akan meng-direct web untuk masuk ke dalam Android Package nya tanpa perlu activity apapun.

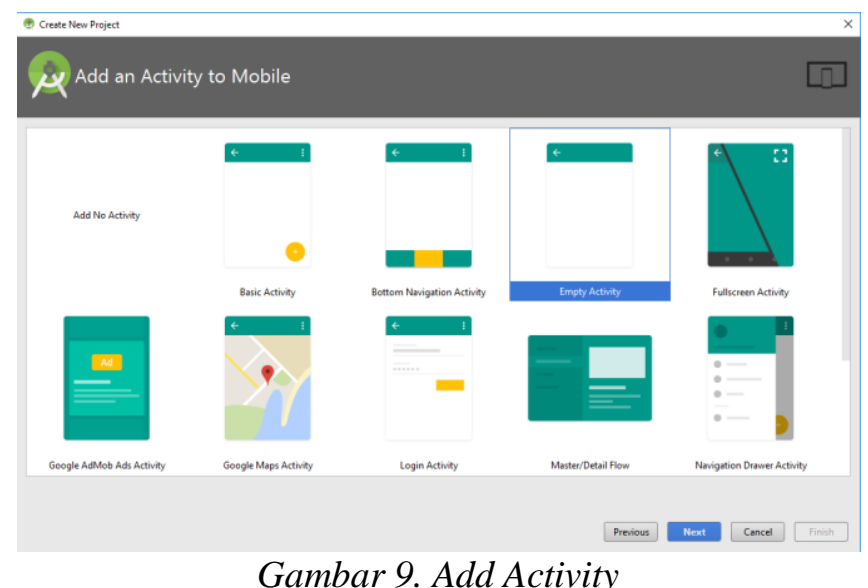

Tahap selanjutnya adalah dengan direct sistem penilaian penplus ke dalam coding Android Studio. Pada folder java dan file main activity, bagian ini harus di isi dengan web yang akan di direct, wajib menambahkan URL web nya pada bagian berikut, webView.loadUrl("http://penplus.raharja.ac.id");. Karena pada bagian ini adalah cara untuk mengdirect atau memanggil sistem yang akan di kemas dalam Android Packaging. 


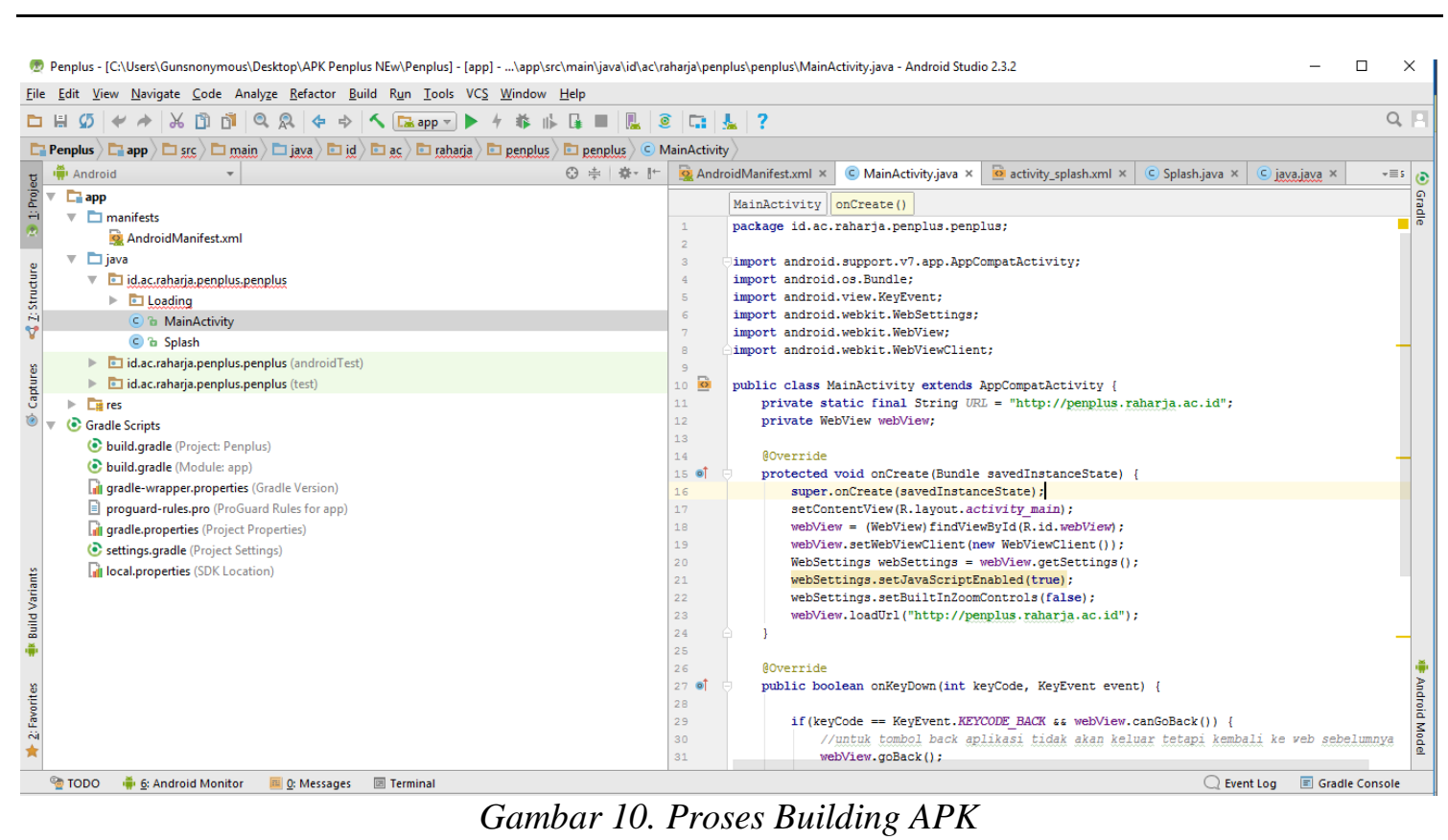

Tahap akhir proses building di lakukan dengan membuild APK hingga selesai. Dalam satu device building, hanya mendapatkan satu keystore yang akan di dapatkan guna menjadi kunci di dalam sistem yang telah di proses. Membuat keystore di lakukan dengan memilih menu Build lalu pilih Generate Signed APK. Setelah langkah sebelumnya selesai, akan muncul kotak dialog Generate Signed APK, disini proses membuat file keystore baru. Keystore digunakan untuk proses autentikasi file dan komunikasi data. Di dalam Android Development, keystore ini sangat vital untuk pengembangan selanjutnya dan dalam hal publishing ke dalam

Play Store. Harus menggunakan keystore yang sama saat akan melakukan update aplikasi, mengganti apk versi lama dengan apk versi baru, dalam arti jika untuk aplikasi versi 1 menggunakan keystore A untuk upload pertama kali, maka untuk aplikasi versi 2 yang merupakan update atau pemutakhiran dari versi 1 juga harus menggunakan keystore A.

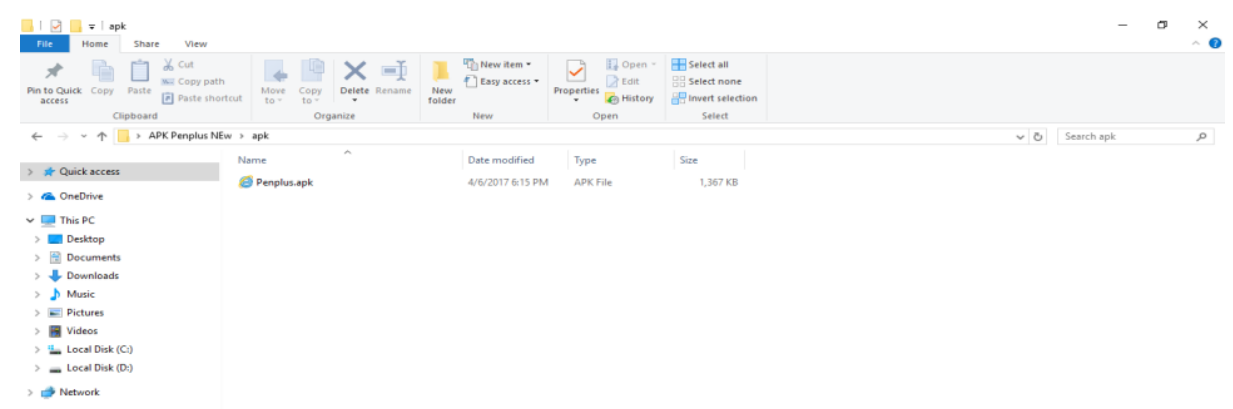

Gambar 11. Hasil Building APK

Sistem penilaian berupa Web telah dikemas dalam Android Packaging. Dengan melewati proses build sebelumnya, Android Packaging ini sudah siap untuk di luncurkan. Hasil yang di dapatkan pun tidak akan berbeda jauh dengan yang versi web nya. Maka dari itu disebut dengan webview. Namun hal ini sangat berguna untuk pengembangan mobile dari mulai dari yang sederhana. 


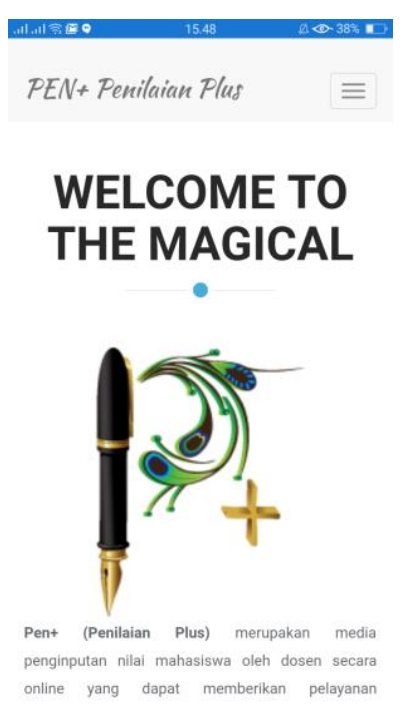

Gambar 12. Tampilan Mobile

Setelah menjadi file Android Packaging dan bisa di akses via mobile device, maka tampilan web pun akan menyesuaikan tampilan nya. Dalam tahap ini tidak hanya mendirect saja, banyak hal yang bisa dilakukan jika ingin menambahkan komponen melalui Android Studio sebagai tools nya.

3.3 Implementasi

Pada tahap implementasi, pemanfaatan Google Play sangat membantu untuk semakin memudahkan pengguna menemukan sistem penilaian melalui Play Store. Maka dari itu, file Android Packaging Pen+ telah di upload ke dalam Play Store. Yang di mana menggambar kan kesuksesan dalam tahap implementasi kepada pengguna. 


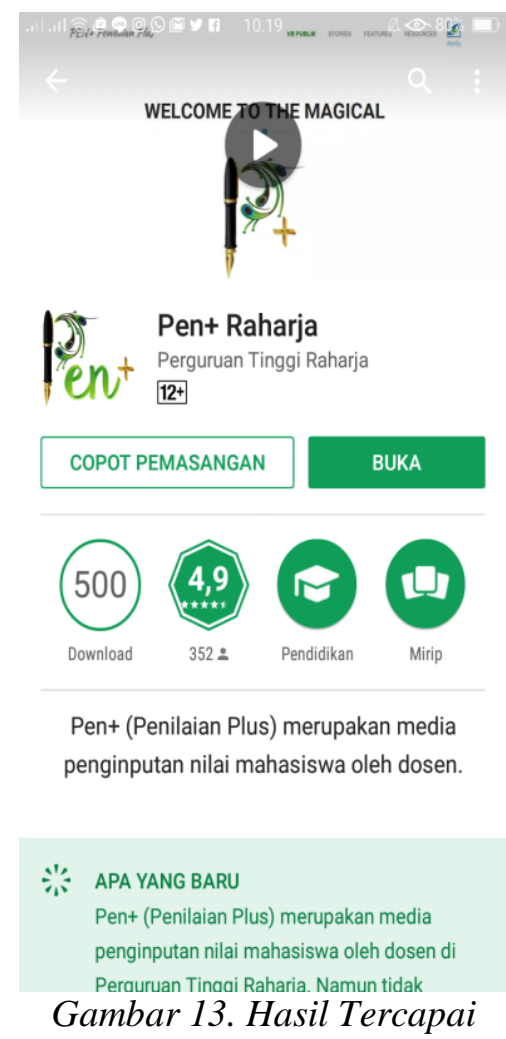

Suatu kesuksesan sistem besar kecilnya bisa di lihat dari seberapa manfaat dan berapa banyak orang yang telah mendapatkan manfaatnya. Begitu pun dengan sistem penilaian Pen+ yang sampai saat ini telah mencapai total Download sebanyak 576 user dan 352 user yang memberikan Rating.

Installs by user (2)

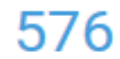

Lifetime
VIEW DETAILS

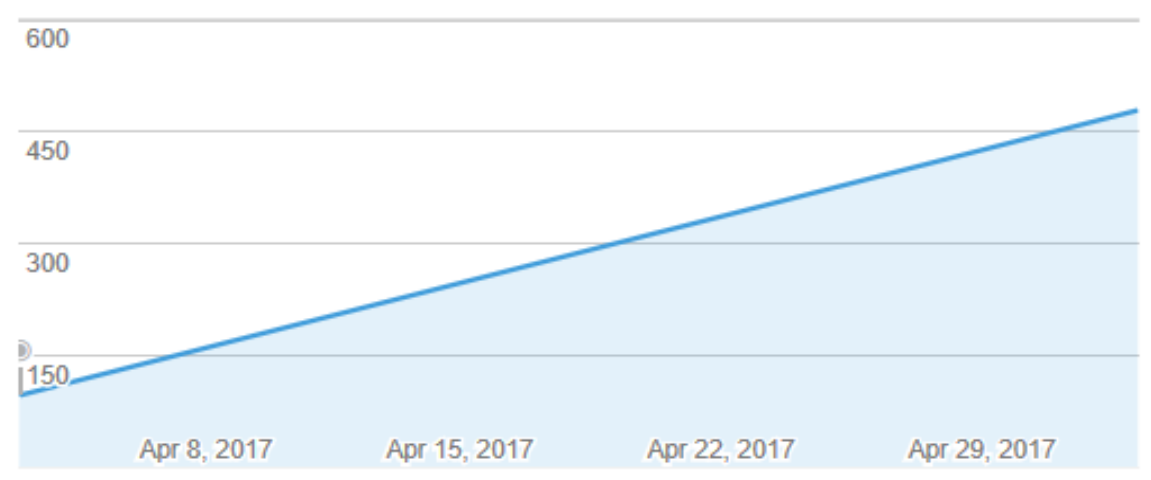

Gambar 14. Statistik Google Play

Berdasarkan statistik di atas, tergambar bahwa melalui Android Packaging mampu 
membuat sebuah web menjadi bisa di gunakan di Mobile Device. Dan pemanfaatan Google Play sangat memaksimalkan penggunaannya.

\section{KESIMPULAN}

Berdasarkan penelitian di atas dapat disimpulkan bahwa membuat file Android Packaging sangat membantu memberikan beragam opsi dalam menggunakan suatu sistem. Begitu pula dengan sistem penilaian yang keberadaan nya sangat vital di dalam suatu lingkup bidang pendidikan. Perkembangan di dunia mobile device pun dapat membantu suatu sistem dalam penggunaan nya. Secara keseluruhan, kesuksesan penelitian di atas dapat di gambarkan dengan banyaknya yang menggunakan yang dapat di lihat di dalam statistik yaitu, 576 User Download dan 352 yang memberikan Rating terhadap sistem penilaian di Perguruan Tinggi Raharja yaitu, Pen+.

\section{SARAN}

Adapun saran untuk penelitian selanjutnya adalah untuk mengembangkan webview ini menjadi sebuah native apps. Yang dimana membutuhkan keahlian yang cukup besar dalam membangun sistem tersebut agar terlihat menjadi lebih baik lagi dari segi tampilan dan penggunaan.

\section{UCAPAN TERIMAKASIH}

Penulis mengucapkan terima kasih kepada Perguruan Tinggi Raharja yang telah memberi dukungan finansial terhadap penelitian ini.

\section{DAFTAR PUSTAKA}

[1] Wijaya, B.D., Fenty, E.M.A. and Fiade, A., (2015). Implementasi JSON Parsing Pada Aplikasi Mobile E-commerce Studi Kasus: CV V3 Tekno Indonesia. Jurnal Pseudocode, 2(1), pp.1-9.

[2] Nugraha, A.H., (2015). Pengembangan Aplikasi Mobile Akademik Dosen Berbasis Webservice di Universitas Widyatama (Doctoral dissertation, Universitas Widyatama).

[3] Saputra, R.D., (2016). Pengembangan Aplikasi Mobile Akademik Mahasiswa Berbasis Web Service di Universitas Widyatama (Doctoral dissertation, Universitas Widyatama).

[4] Nugroho, I.E. and Warsun Najib, S.T., (2015). Purwarupa e-Musrenbang Menggunakan Website dan Aplikasi Mobile Berbasis Android pada Pemerintah Kota Yogyakarta (Doctoral dissertation, Universitas Gadjah Mada).

[5] Anshari, M.K., Arifin, S. and Rahmadiansah, A., (2013). Perancangan Prediktor Cuaca Maritim Berbasis Logika Fuzzy Menggunakan User Interface Android. Jurnal Teknik ITS, 2(2), pp.A324-A328.

[6] Sugiarto, R., Wijana, K. and Handiwidjojo, W., (2015). IMPLEMENTASI MVC PADA SITUS PORTAL PENCARIAN UNIVERSITAS DI DAERAH ISTIMEWA YOGYAKARTA. Jurnal Eksplorasi Karya Sistem Informasi dan Sains, 5(2).

[7] Suharto, U.H., Triyono, J. and Sutanta, E., 2014. Aplikasi Pencarian Lokasi Agen TIKI (Titipan Kilat) Di Yogyakarta Untuk Android. Yogyakarta: Institut Sains dan Teknologi AKPRIND. 